\title{
Effect of Aggregate Properties on Asphalt Concrete Mixes
}

\author{
Abdulrahman S. Al-Suhaibani \\ Civil Eng. Dept., College of Eng., \\ King Saud University, Riyadh, Saudi Arabia
}

\begin{abstract}
The City of Riyadh has witnessed a huge expansion during the last decade. So, roads and streets had to be built to serve the newly-built communities. Demand for high quality aggregate for asphalt pavement construction became an ever increasing problem. Consequently, contractors were directed to obtain aggregate from every possible source. Therefore, a large number of quarries, scattered all around the City of Riyadh, has become the main sources of aggregates. Samples of these quarries were thoroughly studied and compared and their suitability as source for aggregates for asphalt paving mixes production was thoroughly investigated. The results show that there is a significant difference among various sources and not all aggregate sources satisfy Saudi Standards. Furthermore, compaction by Marshall hammer causes some aggregates to disintegrate more than others; indicating somewhat lower quality of these aggregates on one hand, and the disintegration effect of Marshall compaction on the other. Aggregates that disintegrated more have produced higher maximum Marshall stability. Finally, correlation of aggregates' and mixes properties showed that wet Indirect Tensile Strength ( ITS ) and wet resilient Modulus $\left(M_{R}\right)$ were highly correlated both with each other and with a number of aggregate properties.
\end{abstract}

\section{Introduction}

The City of Riyadh has witnessed a huge expansion during the last decade. Consequently, roads and streets had to be built to serve the newly-built communities. Demand for high quality aggregate for asphalt pavement construction became an ever increasing problem. Consequently, contractors were directed to obtain aggregate from every possible source. Therefore, a large number of quarries, scattered all around the city of Riyadh, has become the main sources for aggregates. However, these quarries need to be thoroughly studied and compared and their suitability as 
source for aggregates for asphalt paving mixes production need to be thoroughly investigated. So, it is the purpose of this paper to shed some light on the properties of aggregates representing all quarries located around the city of Riyadh. Furthermore, the effect of aggregate properties on asphalt mixes' properties is discussed.

\section{Background}

Aggregate properties can affect mix properties in different ways. For example, if the aggregates used are weak they may distintegrate easily under the action of Marshall hammer during the mix design process. Consequently, fines and filler content in the mix are increased leading, possibly, to a Marshall stability being higher than usual $^{[1]}$. Gandhi and Lytton ${ }^{[2]}$ investigated large number of aggregate tests and whether these tests can be used as indicators of performance of asphalt concrete mixes. These tests include, but not limited to, Los Angeles abrasion, soundness, sand equivalent, water absorption, and percentage crushed particles. They concluded that some of these tests can be used to judge the quality of aggregates based on a suggested acceptance criterion. Specifically, they mention that aggregate distintegration may very well be linked to the results of Los Angeles abrasion, soundness, and friable particles' tests ${ }^{[2]}$. All these properties can be related to asphalt concrete performance.

As for Riyadh aggregates, most of the conducted studies were oriented toward aggregate use in Portland cement concrete (e.g., Reference [3]) and very few, if any, were directed toward their use in asphalt concrete mixes. There are, also, a number of studies that were conducted by Rashid Geotechnical \& Materials Engineers for a large number of quarry sites around Riyadh and published in a series of reports. These reports contain general information about site lcoation, crusher type and geology. These reports contain, also, the results of borings taken at each site and physical and chemical properties of aggregates taken both from the borings and the crusher. However, no correlation of aggregate properties with asphalt concrete was attempted. Reference [4] is an example of these reports.

\section{Purpose}

The purpose of this study was twofold :

1. To characterize and compare aggregate from different sources in and around the city of Riyadh and to characterize and compare their corresponding asphalt mixes.

2. To correlate aggregate properties with those of asphalt concrete mixtures to predict the behavior of asphalt mixes from aggregate properties.

\subsection{Materials}

\subsubsection{Aggregates}

Nine sources of aggregate representing all quarries used for aggregate production were selected. All nine sources are of limestone type. Quarries are scattered in different wadis around the city of Riyadh. Each wadi usually contains a number of stone crushers. The studied sources were selected after a long discussion with officials from 
Riyadh Municipality and Ministry of Communication (the two Governmental agencies responsible for pavement construction in Riyadh). The sources were selected in such a way that they are representative of all aggregate sources around Riyadh. The locations of the nine aggregate sources are shown in Fig. 1.

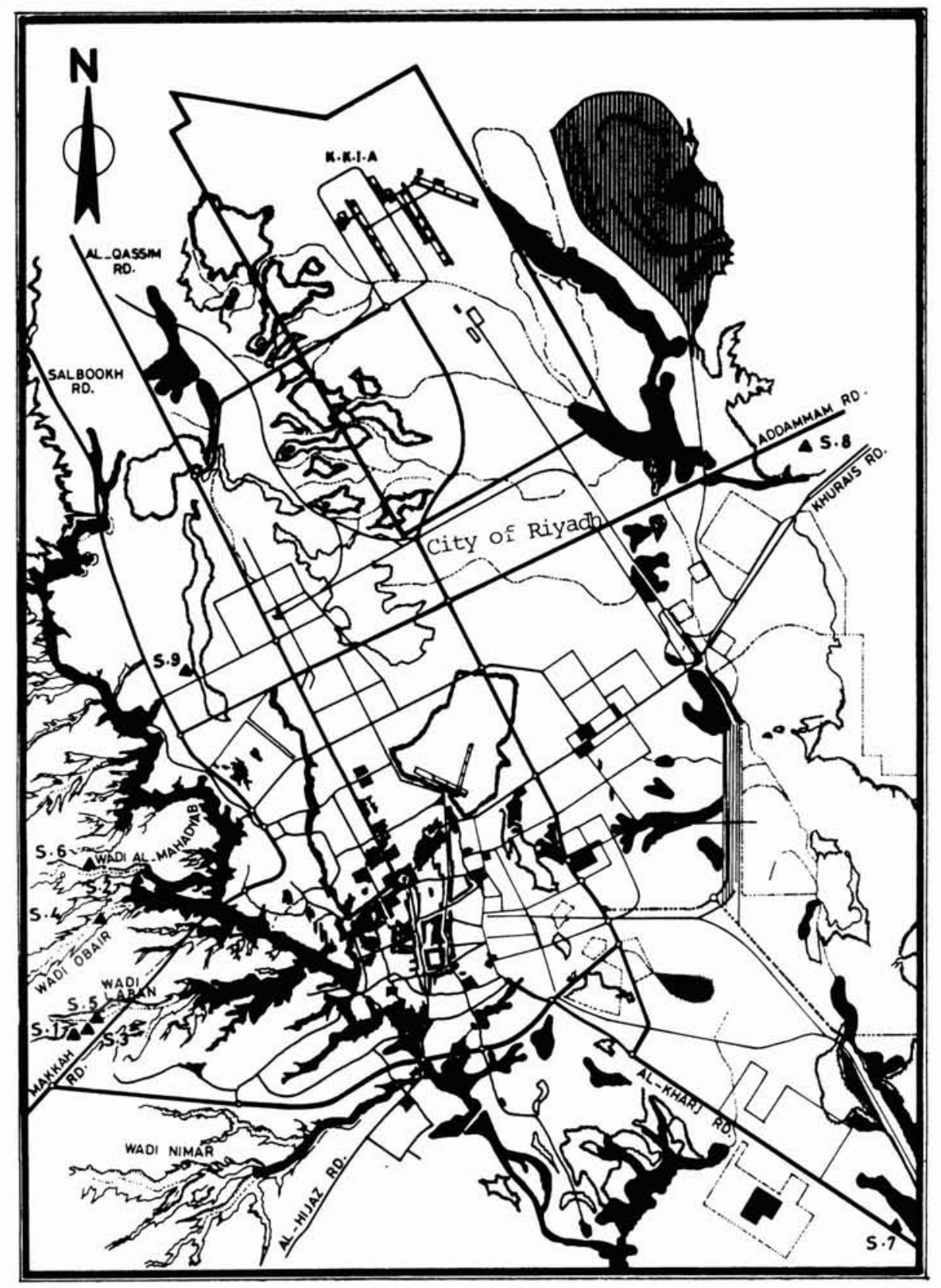

FIG. 1. Location of aggregate sources. 


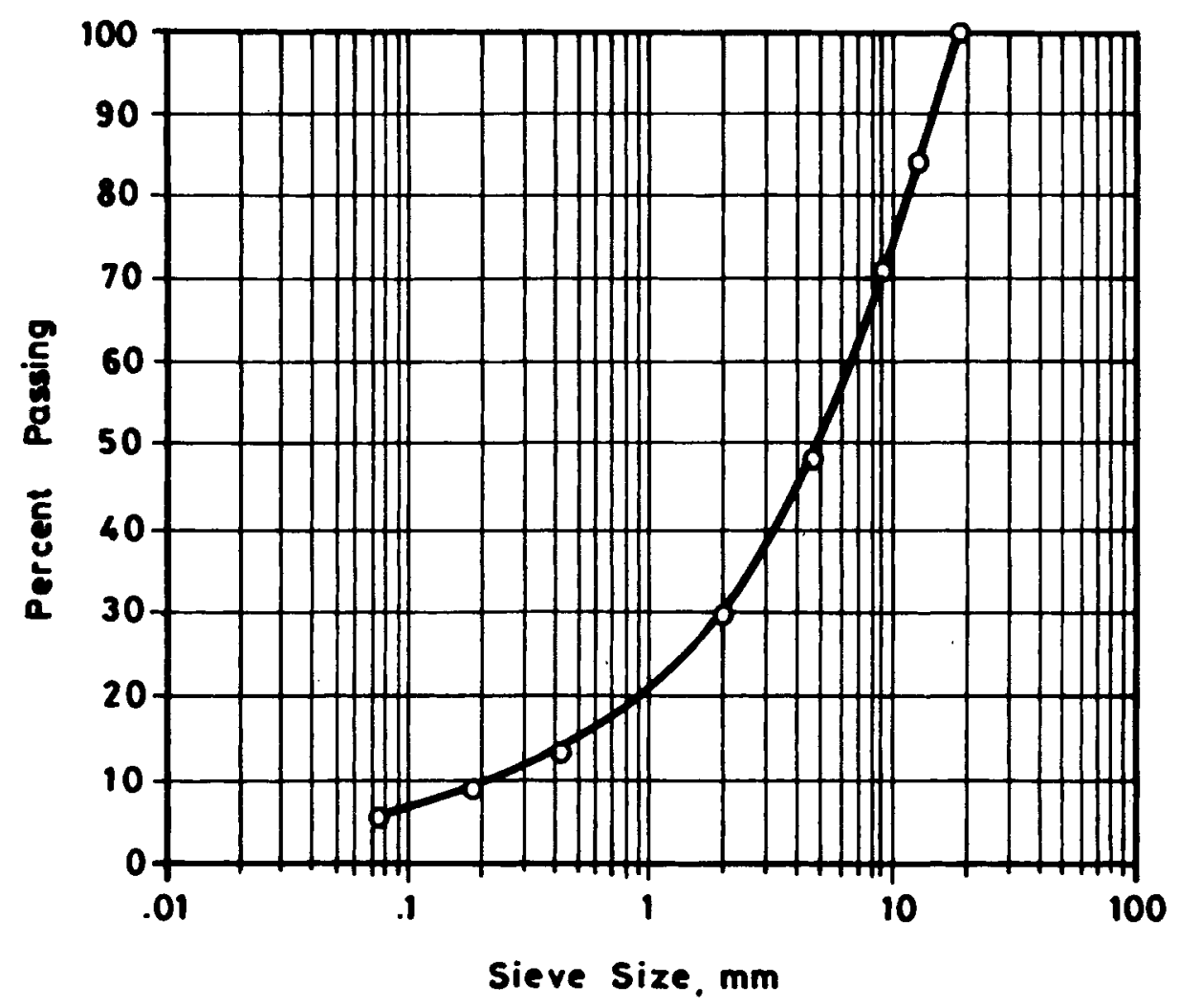

FiG. 2. Aggregate gradation.

Figure 2 shows aggregate gradation that was used for all nine aggregate sources:

\subsubsection{Asphalt}

The Asphalt cement used is a $60-70$ penetration grade and was obtained from Riyadh Refinery. The properties of asphalt are shown in Table 1.

TABLE 1. Properties of asphalt cement.

\begin{tabular}{|l|l|c|}
\hline \multicolumn{1}{|c|}{ Type of test } & \multicolumn{1}{|c|}{$\begin{array}{c}\text { ASTM } \\
\text { designation }\end{array}$} & Test value \\
\hline 1. Penetration, $100 \mathrm{~g}, 5 \mathrm{sec}$ & $\mathrm{D} 5-86$ & 60 \\
2. Kinematic viscosity, at $135^{\circ} \mathrm{C}$ (cst) & $\mathrm{D} 2170-85$ & 403 \\
3. Absolute viscosity at $60^{\circ} \mathrm{C}$ (poises) & $\mathrm{D} 2171-85$ & 2459 \\
4. Softening point, ${ }^{\circ} \mathrm{C}$ & $\mathrm{D} 36-86$ & 50 \\
5. Ductility, cm & $\mathrm{D} 113-85$ & $100+$ \\
6. Specific gravity & $\mathrm{D} 70-82$ & 1.035 \\
7. Flash point, ${ }^{\circ} \mathrm{C}$ & $\mathrm{D} 92-85$ & 340 \\
8. Fire point, ${ }^{\circ} \mathrm{C}$ & $\mathrm{D} 92-85$ & 370 \\
\hline
\end{tabular}




\subsection{Laboratory Testing of Aggregates}

Aggregates from different sources were subjected to a number of tests. These tests were as follows :

1) Specific gravity and water absorption (ASTM C 127, 128-84).

2) Los Angeles abrasion test (ASTM C 535-81).

3) Sand equivalent (ASTM D 2419-79).

4) Soundness (using sodium sulphate) (ASTM C 88-83).

5) Particle size distribution after mixing and compaction.

6) Crushing value (B.S. 812: Part 3, 1975).

7) Aggregate surface constants ( $K_{m}$ ) (MS-2, The Asphalt Institute).

The results of these tests are shown in Table 2 . The determination of particle size distribution after mixing and compaction was intended to investigate the susceptibility of various aggregates to disintegration under the action of Marshall compactor. The increase in percentage passing for each sieve was calculated then multiplied by the corresponding surface area factor (Hveem mix design method) to obtain the increase in surface area for each sieve. The total increase in surface area was then obtained by summing up individual surface areas for each sieves. The aggregate surface constant was obtained using the procedure described in MS-2 of the Asphalt Institute as part of the Hveem design method to estimate asphalt content.

TABLE 2. Aggregate properties.

\begin{tabular}{|c|c|c|c|c|c|c|c|}
\hline $\begin{array}{c}\text { Aggregate } \\
\text { source }\end{array}$ & $\begin{array}{c}\text { LA } \\
\text { abrasion } \\
\text { loss \% }\end{array}$ & $\begin{array}{c}\text { Sand } \\
\text { equivalent } \\
\%\end{array}$ & $\begin{array}{c}\text { Soundness } \\
\%\end{array}$ & $\begin{array}{c}\text { Water } \\
\text { absorption } \\
\%\end{array}$ & $G_{s b}$ & $\begin{array}{c}\text { Crush. } \\
\text { value } \\
\%\end{array}$ & $\begin{array}{c}\text { Surface } \\
\text { constant } \\
K_{m}\end{array}$ \\
\hline & & & & & & & \\
2 & 25.7 & 25 & 4.03 & 2.292 & 2.530 & 24.98 & 1.0 \\
3 & 29.4 & 31 & 4.56 & 2.340 & 2.530 & 29.99 & 1.2 \\
4 & 25.3 & 56 & 3.34 & 1.562 & 2.568 & 24.44 & 1.3 \\
5 & 28.5 & 69 & 5.63 & 2.062 & 2.542 & 26.09 & 1.3 \\
6 & 23.0 & 31 & 2.78 & 1.920 & 2.567 & $27 . w$ & 1.2 \\
7 & 25.7 & 55 & 7.11 & 2.460 & 2.527 & 27.83 & 1.1 \\
8 & 24.1 & 61 & 4.43 & 1.677 & 2.588 & 26.21 & 1.2 \\
9 & 24.3 & 65 & 11.10 & 1.955 & 2.578 & 27.62 & 1.2 \\
Saudi & 35.9 & 44 & 20.61 & 4.246 & 2.473 & 28.07 & 1.5 \\
standards & 40 max. & 45 min. & 10 max. & - & - & - & - \\
\hline
\end{tabular}

Note: Date for some of the sources are taken from Reference [5].

Aggregate test results will be analyzed and discussed when the results of mixes are discussed.

\subsection{Asphalt Mixes}

Marshall mix design method was used to design asphalt concrete mixes using aggregates from different sources. Mixes at $4 \%$ air voids were then made for each 
aggregate type. These mixes were then subjected to the indirect tensile and resilient modulus tests both before and after water conditioning.

It was demonstrated ${ }^{[5]}$ that curing asphalt concrete specimens for 3 days in an oven maintained at $60^{\circ} \mathrm{C}$ brings their strength to a stable value. This procedure was followed in this study to insure that specimens soaked in a $60^{\circ} \mathrm{C}$ water bath will not gain any strength due to hardening of asphalt caused by immersion in hot water. If the later case occurs it might overshadow any loss in strength due to water action (stripping); and the total effect will be an increase in strength for soaked specimens solely due to hardening of asphalt.

Cured specimens were then tested both in dry condition and after being soaked in a water bath maintained at $60^{\circ} \mathrm{C}$ for $24 \mathrm{hr}$. To speed up the process of testing soaked specimens, they were put in a water bath maintained at room temperature for $2 \mathrm{hr}$ before being tested. Both dry and soaked specimens were tested for indirect tensile strength ( ITS ) and resilient modulus ( $\left.M_{R}\right)$. Given the non-destructive nature of the resilient modulus test, same specimens were tested for dry and soaked condition. This would eliminate errors caused by material variability.

\section{Analysis and Discussion}

\subsection{Aggregate Properties}

There was large number of properties of both aggregates and mixes that had to be studied. First, aggregate properties are evaluated. Table 2 presents aggregate properties together with limits prescribed by Saudi Standard.

Results show that all aggregates satisfy the $40 \%$ max. for loss in Los Angeles abrasion test while only sources 8 and 9 exceed the max. $10 \%$ for loss in the soundness test. Sand equivalent test is satisfied by all aggregates except 2, 5 and 9 where they fall short of the $45 \% \mathrm{~min}$. value. Water absorption values show that sources 2 and 9 gave remarkably high values, much higher than other sources. In general, there is no consistency in results for various aggregates except for source 9. The rating for source 9 is low for most tests although it satisfies the requirement for loss in abrasion test. As for specific gravities (effective and bulk), aggregates show some variation, although not large, except for the ninth source which possesses a somewhat lower bulk specific gravity than others. This means it is of higher voids and consequently weaker aggregates. This confirms the above statement about the ninth source of being a lower quality.

\subsection{Mix Properties vs. Aggregate Properties}

Different aggregates were mixed with asphalt at different asphalt percentages for the purpose of obtaining the design asphalt content for each aggregate. Then for each aggregate and at four percent air voids six specimens were casted. After being cured as mentioned earlier, three of the specimens were tested for dry resilient modulus $\left(M_{R}\right)$. These specimens were, then, soaked for the specified period and at the specified conditions and then tested for wet $\left(M_{R}\right)$ and wet ITS. The other three specimens were tested for dry ITS. Test results are shown in Table 3. 
TABLE 3. Properties of asphalt concrete mixes.

\begin{tabular}{|c|c|c|c|c|c|c|c|c|}
\hline $\begin{array}{l}\text { Aggregate } \\
\text { source }\end{array}$ & $\begin{array}{c}A C @ \\
4 \% A V\end{array}$ & $\begin{array}{c}\text { Max. } \\
\text { M.St. kN }\end{array}$ & $\begin{array}{c}\text { DITS } \\
\mathrm{kPa} \times 10^{3}\end{array}$ & $\begin{array}{c}\text { WITS } \\
\mathrm{kPa} \times 10^{3}\end{array}$ & $\begin{array}{c}D M_{R} \\
\mathrm{kPa} \times 10^{6}\end{array}$ & $\begin{array}{c}W M_{R} \\
\mathrm{kPa} \times 10^{6}\end{array}$ & RITS & $R M_{R}$ \\
\hline 1 & 4.4 & 16.14 & 1.180 & 0.914 & 7.084 & 3.896 & 0.777 & 0.549 \\
\hline 2 & 4.2 & 22.21 & 1.159 & 1.050 & 5.419 & 4.404 & 0.907 & 0.815 \\
\hline 3 & 4.5 & 18.65 & 1.231 & 1.145 & 5.711 & 5.562 & 0.931 & 0.974 \\
\hline 4 & 4.7 & 15.87 & 1.300 & 0.999 & 6.116 & 4.489 & 0.769 & 0.730 \\
\hline 5 & 4.7 & 17.48 & 1.207 & 1.039 & 5.849 & 5.262 & 0.861 & 0.900 \\
\hline 6 & 4.4 & 14.43 & 1.147 & 1.127 & 5.293 & 4.443 & 0.984 & 0.841 \\
\hline 7 & 3.6 & 16.91 & 1.150 & 0.973 & 4.867 & 4.570 & 0.848 & 0.940 \\
\hline 8 & 4.1 & 13.15 & 1.250 & 0.947 & 6.730 & 4.320 & 0.756 & 0.645 \\
\hline 9 & 5.2 & 24.63 & 1.137 & 0.760 & 5.227 & 3.477 & 0.676 & 0.681 \\
\hline
\end{tabular}

Note: Data for some of the sources are taken from Reference [5].

TABLE 3. Contd.

\begin{tabular}{|c|c|c|c|}
\hline $\begin{array}{c}\text { Aggregate } \\
\text { source }\end{array}$ & $\begin{array}{c}\text { Added surface } \\
\text { area, } \mathrm{m}^{2} / \mathrm{kg}\end{array}$ & $\begin{array}{c}\text { Absorbed asphalt } \\
\%\end{array}$ & $\begin{array}{c}\text { Actual film } \\
\text { thickness, } \mu \text {-in. }\end{array}$ \\
\hline & & 1.7 & \\
1 & 0.65 & 1.8 & 5.02 \\
2 & 1.99 & 0.9 & 3.58 \\
3 & 2.09 & 1.3 & 5.09 \\
4 & 1.67 & 1.2 & 5.31 \\
5 & 1.78 & 1.4 & 5.23 \\
6 & 1.81 & 0.4 & 4.64 \\
7 & 1.06 & 1.2 & 5.35 \\
8 & 1.60 & 2.9 & 4.44 \\
9 & 4.59 & 2.61 \\
\hline
\end{tabular}

To check whether mixes made from different sources of aggregates are different, a one way analysis of variance (ANOVA) was conducted on mix properties, namely; dry and wet $I T S$, dry and wet $M_{R}$, and retained $I T S$ and $M_{R}$. The results are shown in Table 4 . All above properties, except dry ITS, show that there are significant differences among various mixes at $95 \%$ confidence level. It follows that since these mixes are different, so it is worthwhile to study the effect of aggregate properties on such mixes, which is the subject of the following paragraphs.

Specimens after being tested were subjected to extraction test to extract asphalt cement so that an evaluation of any change in aggregate gradation can be made. This was done according to ASTM D 2172. Aggregates were then sieved on the same sieves used to separate aggregate into fractions for mixes' preparation. Comparison of the two gradations (before and after mixing and compaction) was made and the results are presented in terms of the extra aggregate surface area caused by the disintegration of aggregate due to mixing and compaction. The results are shown in Table 3. 
TABLE 4. One-way analysis of variance for mixes properties.

\begin{tabular}{|c|c|c|c|c|c|}
\hline \multicolumn{6}{|c|}{ Dry indirect tensile strength ( ITS ) } \\
\hline $\begin{array}{l}\text { Source of } \\
\text { variation }\end{array}$ & $\begin{array}{l}\text { Sum of } \\
\text { squares }\end{array}$ & D.F. & $\begin{array}{c}\text { Mean } \\
\text { square }\end{array}$ & F-ratio & $\begin{array}{l}\text { Sig. } \\
\text { level }\end{array}$ \\
\hline $\begin{array}{l}\text { Between groups } \\
\text { Within groups } \\
\text { Total (corrected) }\end{array}$ & $\begin{array}{l}0.0742 \\
0.0850 \\
0.1591\end{array}$ & $\begin{array}{r}8 \\
18 \\
26\end{array}$ & $\begin{array}{l}0.0093 \\
0.0047\end{array}$ & 1.964 & 0.1117 \\
\hline \multicolumn{6}{|c|}{ Wet ITS } \\
\hline $\begin{array}{l}\text { Between groups } \\
\text { Within groups } \\
\text { Total (corrected) }\end{array}$ & $\begin{array}{l}0.3279 \\
0.1513 \\
0.4792\end{array}$ & $\begin{array}{r}8 \\
18 \\
26\end{array}$ & $\begin{array}{l}0.4099 \\
0.0084\end{array}$ & 4.875 & 0.0025 \\
\hline \multicolumn{6}{|c|}{ Retained ITS } \\
\hline $\begin{array}{l}\text { Between groups } \\
\text { Within groups } \\
\text { Total (corrected) }\end{array}$ & $\begin{array}{l}0.2302 \\
0.1476 \\
0.3778\end{array}$ & $\begin{array}{r}8 \\
18 \\
26\end{array}$ & $\begin{array}{l}0.0287 \\
0.0082\end{array}$ & 3.511 & 0.0128 \\
\hline \multicolumn{6}{|c|}{ Dry resilient modulus $\left(M_{R}\right)$} \\
\hline $\begin{array}{l}\text { Between groups } \\
\text { Within groups } \\
\text { Total (corrected) }\end{array}$ & $\begin{array}{c}12.670 \\
4.7698 \\
17.439\end{array}$ & $\begin{array}{r}8 \\
18 \\
26\end{array}$ & $\begin{array}{l}1.5837 \\
0.2650\end{array}$ & 5.976 & 0.0008 \\
\hline \multicolumn{6}{|c|}{ Wet $M_{R}$} \\
\hline $\begin{array}{l}\text { Between groups } \\
\text { Within groups } \\
\text { Total (corrected) }\end{array}$ & $\begin{array}{r}9.5108 \\
6.3963 \\
15.907\end{array}$ & $\begin{array}{r}8 \\
18 \\
26\end{array}$ & $\begin{array}{l}1.1890 \\
0.3553\end{array}$ & 3.346 & 0.0159 \\
\hline \multicolumn{6}{|c|}{ Retained $\boldsymbol{M}_{R}$} \\
\hline $\begin{array}{l}\text { Between groups } \\
\text { Within groups } \\
\text { Total (corrected) }\end{array}$ & $\begin{array}{l}0.4961 \\
0.1909 \\
0.6870\end{array}$ & $\begin{array}{r}8 \\
18 \\
26\end{array}$ & $\begin{array}{l}0.0620 \\
0.0106\end{array}$ & 5.848 & 0.0009 \\
\hline
\end{tabular}

The disintegration of aggregate, which is believed to be mainly due to the hammering action of the Marshall compactor, raises some questions about the extent to which this type of laboratory compaction simulates that of the field. It was indicated $^{[6,7]}$ that other types of compaction, e.g., California kneading compaction, may better simulate field compaction.

Also shown in Table 3 are the percentage asphalt absorption and the actual film thickness which is based on actual film thickness (considering extra surface area).

At the beginning a correlation matrix was prepared for aggregates' and mixes' properties. The correlation matrix for highly correlated properties (significant level $90 \%$ ) is shown in Table 5. It is obvious that some properties such as dry $M_{R}$, dry ITS 
and sand equivalent do not appear in the table, meaning that they are not highly correlated with any other property. However, presenting results in a graphical form will show a more clear picture of the relationships between properties of mixes and those of aggregates. Some of the important relationships which deserve further discussion were plotted and are shown in Fig. 3-11.

TABLE 5. Correlation matrix for highly correlated properties.

\begin{tabular}{|c|c|c|c|c|c|c|c|c|c|c|c|c|c|}
\hline $\begin{array}{c}\text { Variable } \\
s\end{array}$ & 123 & 4 & 5 & 6 & 7 & 8 & 9 & 10 & 11 & 12 & 13 & 14 & 15 \\
\hline 1 & $1--$ & - & - & - & - & 0.77 & 0.72 & - & - & 0.69 & -0.75 & - & - \\
\hline 2 & $1-$ & - & - & - & -0.74 & - & 0.74 & 0.78 & - & - & - & - & - \\
\hline 3 & 1 & 0.81 & 0.92 & - & - & - & - & - & - & -0.71 & - & - & - \\
\hline 4 & & 1 & - & 0.78 & - & 0.70 & - & - & -0.70 & -0.76 & 0.70 & - & - \\
\hline 5 & & & 1 & 0.70 & - & - & - & - & - & - & - & - & - \\
\hline 6 & & & & 1 & - & - & - & - & - & - & - & - & - \\
\hline 7 & & & & & 1 & -0.87 & -0.82 & -0.84 & -0.80 & -0.86 & 0.77 & -0.74 & - \\
\hline 8 & & & & & & 1 & 0.75 & 0.86 & 0.74 & 0.92 & -0.87 & - & - \\
\hline 9 & & & & & & & 1 & 0.83 & 0.82 & 0.83 & -0.82 & - & 0.86 \\
\hline 10 & & & & & & & & 1 & 0.76 & 0.89 & -0.88 & - & 0.70 \\
\hline 11 & & & & & & & & & 1 & 0.86 & -0.66 & - & - \\
\hline 12 & & & & & & & & & & 1 & -0.92 & - & - \\
\hline 13 & & & & & & & & & & & 1 & - & - \\
\hline 14 & & & & & & & & & & & & 1 & - \\
\hline 15 & & & & & & & & & & & & & 1 \\
\hline
\end{tabular}

$1-A C @ 4 \%, A V, 2$ - Max. Marshall stab., 3-Wet ITS, 4- Wet $M_{R}, 5$ - Ret. ITS, 6 - Ret. $M_{R}, 7$ - Actual film th., 8Absorbed asphalt, 9 - Added surf. area, 10 - Abrasion loss, 11 - Soundness, 12 - Wtr. absrp., 13 - Bulk sp. gr., 14 Crushing val., $15-$ Surf. const.

Before discussing relationships among variables it should be mentioned that not all high correlations deserve attention, since some of the variables are logically related (e.g., one is calculated from the other). So, these types of relationships will not be discussed. In the following paragraphs the important relationships are discussed.

\subsection{Asphalt Content at 4\% Air Voids}

This property is highly correlated with absorbed asphalt (Pba), added surface area, loss due to Los Angeles abrasion test, water absorption, and bulk specific gravity of aggregate. The high correlation of $A C @ 4 \%$ air voids with both the added surface area and Los Angeles abrasion loss is logical. Both the added surface area and Los Angeles abrasion loss are related to the weakness of the aggregate. Thus the increase in surface area to the increase in fines affects the asphalt content. The relationship between $A C @ 4 \%$ air voids and the absorbed asphalt (Pba),water absorption, and bulk specific gravity (all three are related to each other) is mainly because all three variables are related to aggregate surface voids. As the aggregate surface voids increase, the demand to fill these voids increases, thus increasing the total demand for asphalt. So, it can be concluded that as the Los Angeles abrasion loss increases, and/or as the bulk specific gravity decreases the aggregate demand for asphalt increases; thus higher design asphalt content is required. 


\subsection{Maximum Marshall Stability}

Maximum Marshall stability is highly correlated with both Los Angeles abrasion loss and the added surface area as shown in Fig. 3 and 4, respectively. Figure 3 shows that the higher the Los Angeles abrasion loss the higher the stability. This clearly indicates that weaker aggregates might produce higher Marshall stability mixes (provided these mixes were compacted by Marshall hammer). So, high Marshall stability might indicate that low quality aggregates were used in such mixes. Brown et al ${ }^{[1]}$ reported that high Marshall stability is usually associated with mixes having high filler content. This confirms the above statement. It should be mentioned here that mixes with high Marshall stabilities are also not recommended because of their brittleness which makes them highly susceptible to fatigue cracking.

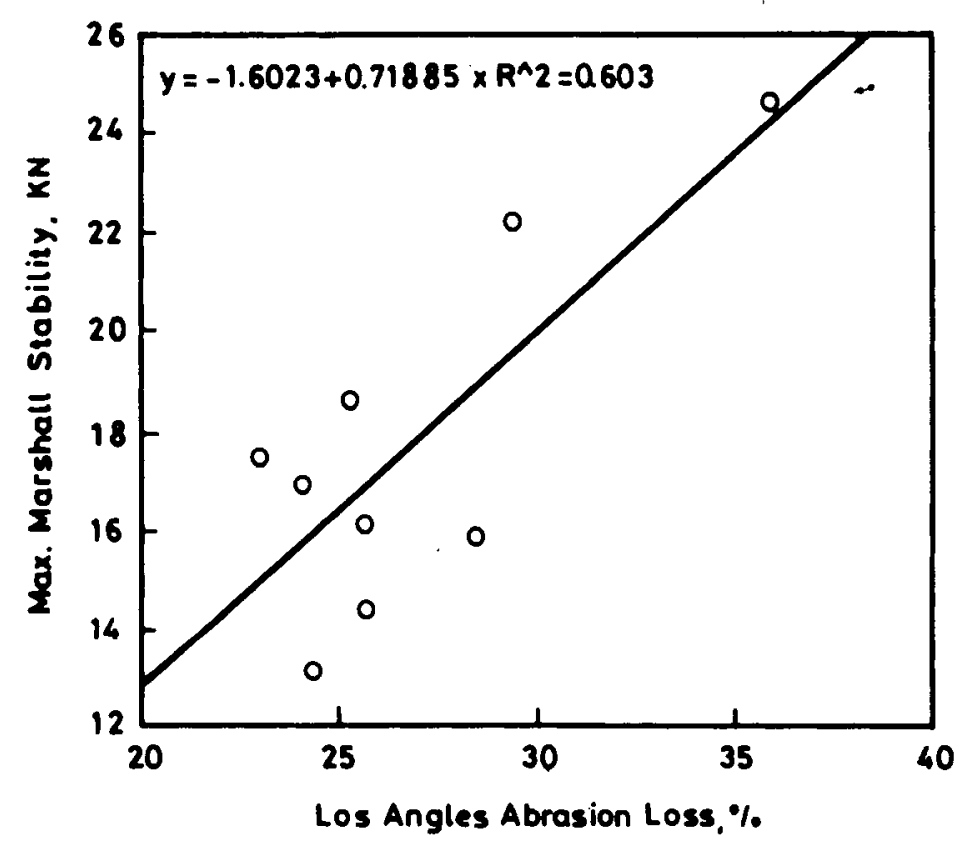

FIg. 3. Max. Marshall stábility vs. Los Angeles abrasion loss.

Other aggregate properties correlated with max. Marshall stability is more or less related to the above two aggregate properties.

\subsection{Indirect Tensile Strength and Resilient Modulus}

As was mentioned before, dry ITS and dry $M_{R}$ do not appear in Table 5 meaning they are not highly correlated with any other mix or aggregate property. This means no single property value can be used to predict the value of either one of these two 


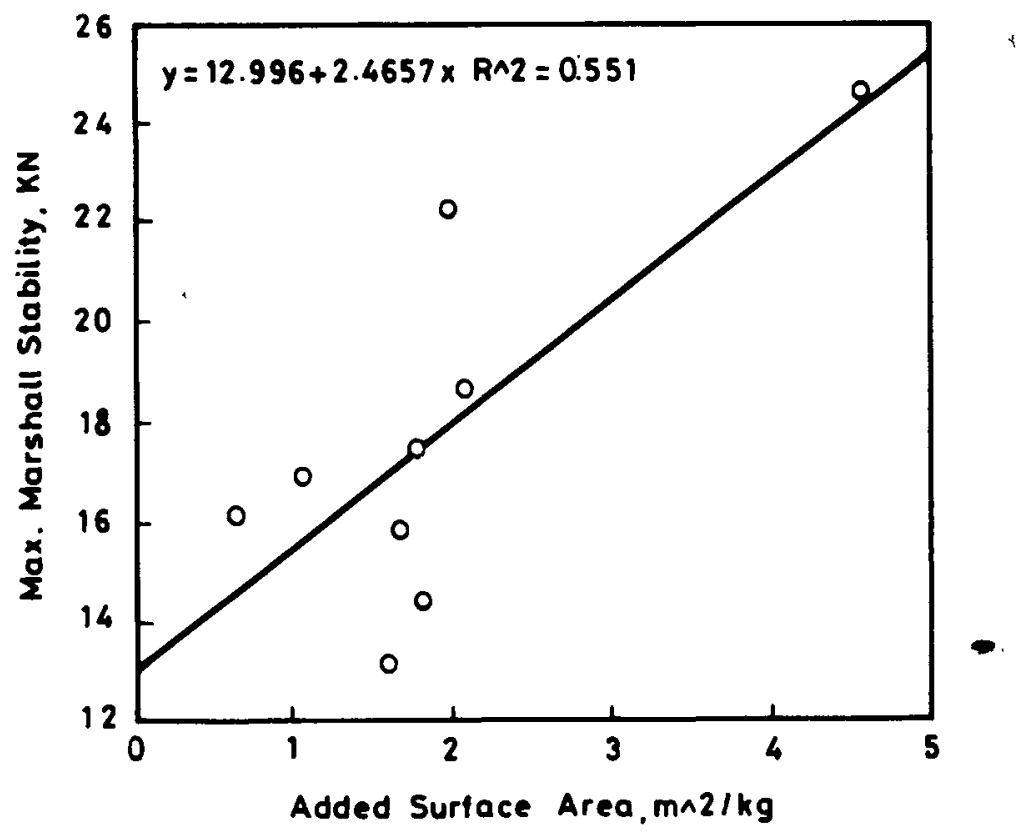

FIG. 4. Max. Marshall stability vs. added surface area.

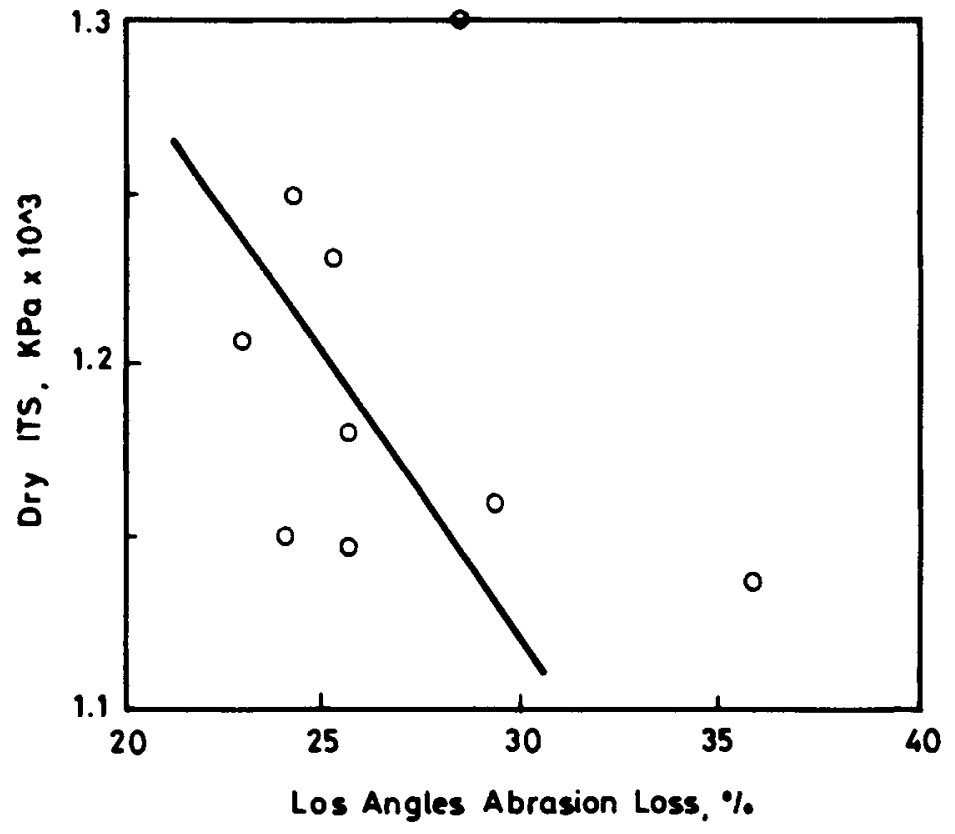

FIG. 5. Dry indirect tensile strength vs. Los Angeles abrasion loss. 
properties. However, a number of properties may affect the values of these two properties. For example, Fig. 5 and 6 show, generally, that the values of dry ITS and $M_{R}$ decrease as Los Angeles abrasion loss increases. Although points are widely scattered, this trend is supported by the fact that mixes made with low quality aggregates (high abrasion loss) are, generally, weak mixes and in turn possess lower ITS and $M_{R}$ values.

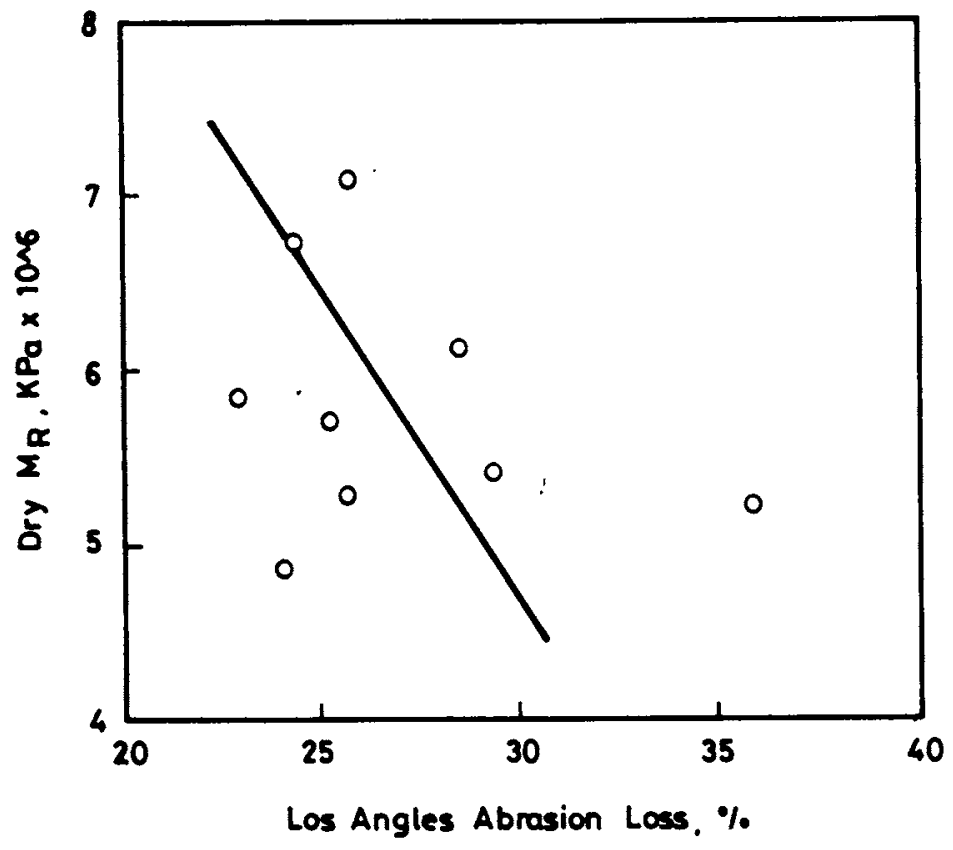

Fig. 6. Dry resilient modulus vs. Los Angeles abrasion loss.

Dry ITS and $M_{R}$ are inversely related to aggregate soundness as shown in Fig. 7 and 8 . This confirms the above relationship between these two properties and abrasion loss since both the abrasion loss and soundness describe the susceptibility of aggregate to weathering and disintegration.

In contrast with dry $I T S$ and $M_{R}$, wet $I T S$ and $M_{R}$ are highly correlated with a number of aggregate property values such as water absorption, film thickness ... , etc. This is believed to be mainly due to the effect that the water has on these two properties as the quality of aggregate goes down which is very much related, for example, to water absorption and film thickness. The general trend is the same as that for dry ITS and $M_{R}$. There is a decrease in wet $I T S$ and $M_{R}$ as the quality of aggregate goes down (as represented by high abrasion loss, high soundness loss, high water absorption, ... etc). The trend is shown in Fig. 9 and 10 for aggregate soundness with wet $I T S$ and $M_{R}$, respectively. This behavior is believed to be caused by the increased in the fine portion of the aggregate, due to the hammering compaction, as the aggregate quality goes down. 


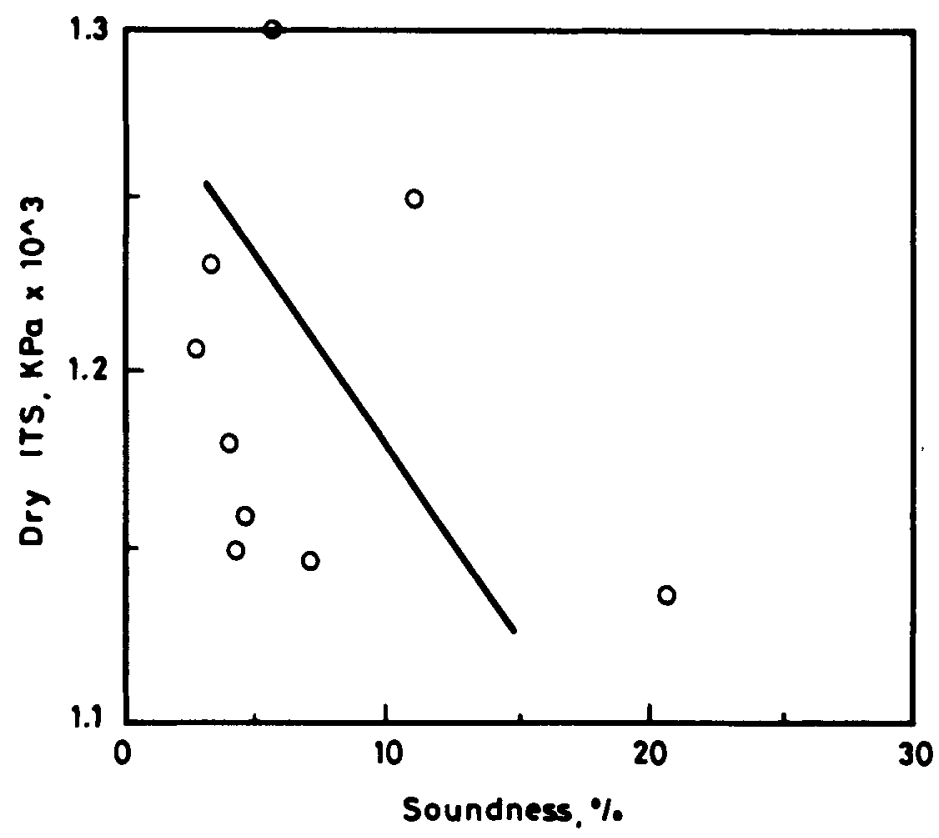

FIG. 7. Dry indirect tensile strength vs. soundness.

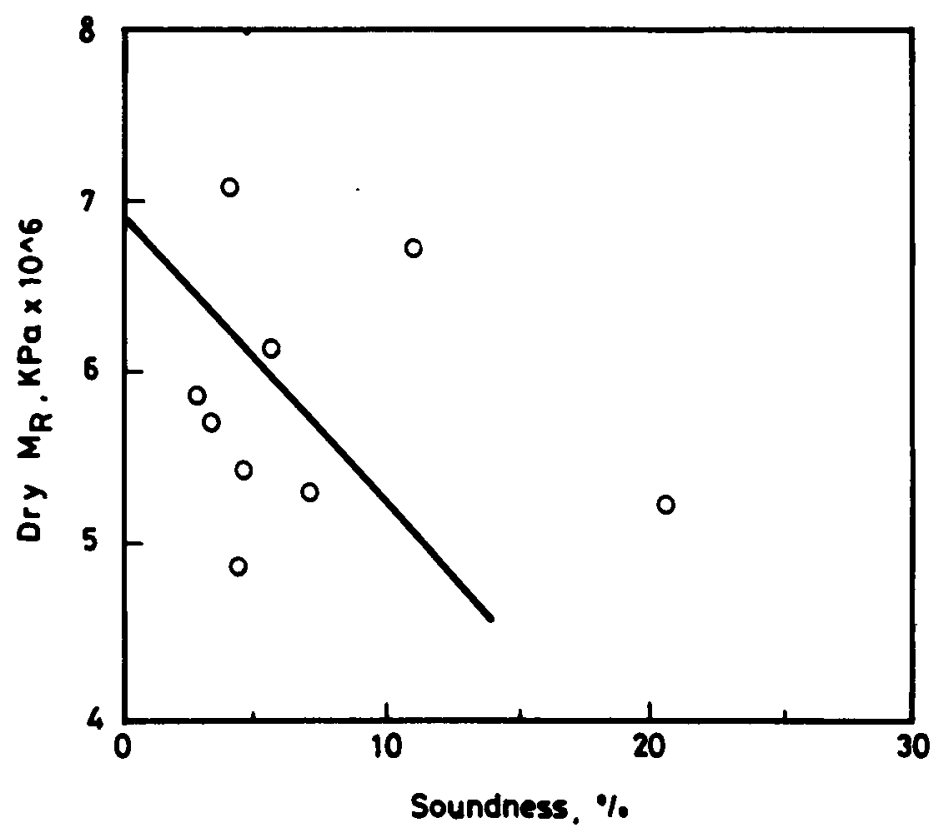

FIG. 8. Dry resilient modulus vs. soundness. 


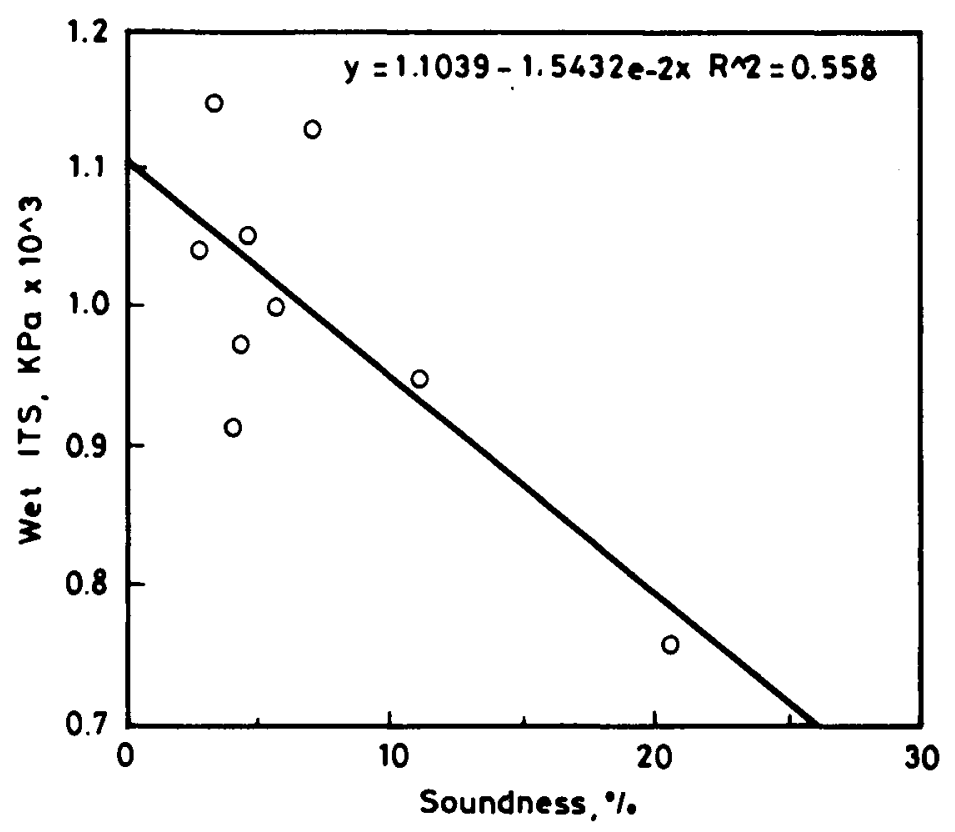

Fig. 9. Wet indirect tensile strength vs. soundness.

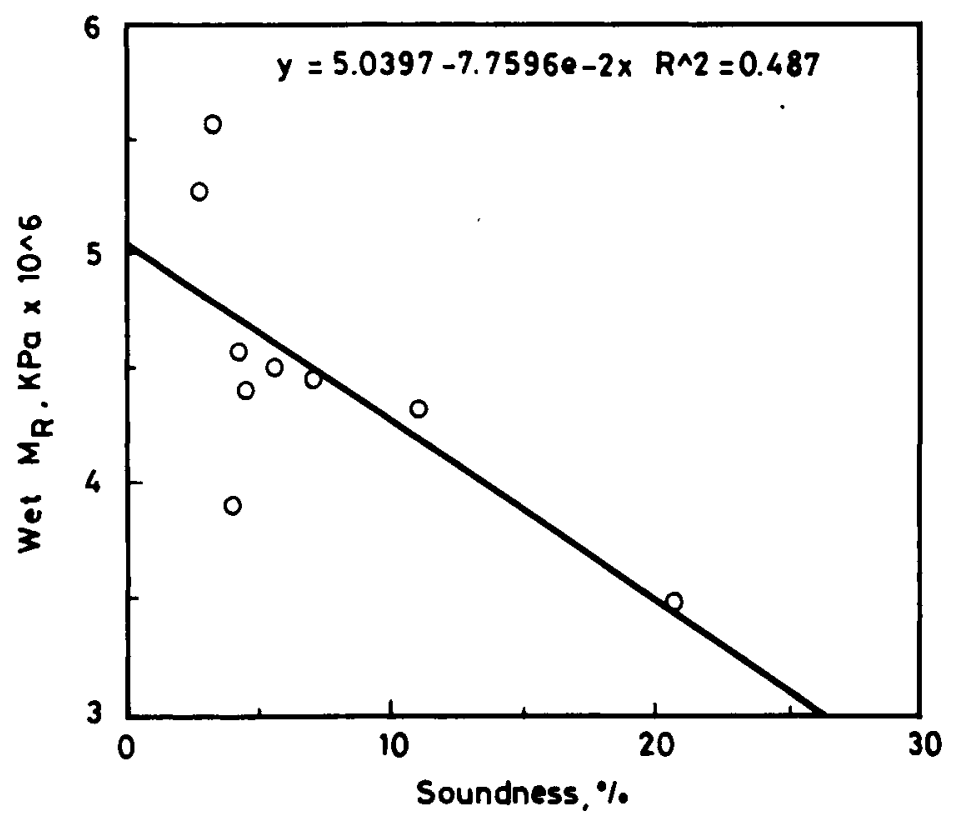

FIG. 10. Wet resilient modulus vs. soundness. 
The dependency of wet ITS and $M_{R}$ on such aggregate properties indicates the need for water effect evaluation of bituminous mixes before they can be accepted for paving; especially, in areas where pavement is to be highly exposed to water. The high correlation of both properties with water absorption emphasizes this need.

The correlation matrix shows that wet ITS and wet $M_{R}$ are very highly correlated to each other $(r=0.81)$ meaning that one can be used to predict the other. This suggests that there is no need to perform both tests for water action evaluation.

The correlation matrix indicates that retained ITS and retained $M_{R}$ are not highly correlated with many variables as was the case with wet ITS and wet $\boldsymbol{M}_{R}$. This is probably due to the interaction between dry and wet values of ITS and $M_{R}$ which were used to calculate retained values. Both properties, dry ITS and dry $M_{R}$, were found not to be highly correlated with any other single variable as discussed before.

\subsection{Correlation of Aggregate Properties}

As for aggregate properties, the correlation matrix shows high correlations among added surface area, Los Angeles abrasion loss, soundness, water absorption, and bulk specific gravity. The high correlation of abrasion loss with added surface area indicates the susceptibility of low quality aggregates to disintegration under compaction as its abrasion loss increase.

Also high correlation among abrasion loss, soundness, water absorption, and bulk specific gravity aggregate means that any one of these properties can be used as an indication of the others. So, it may not be necessary to conduct all these tests especially Los Angeles and soundness tests since one can be used to predict reasonably well the other. An example of these relationships is shown in Fig. 11 for soundness vs. abrasion loss.

Crushing value, which was obtained following British Standard (B.S. 812) procedure, was found to be negatively correlated with actual film thickness. There is no other high correlation found between crushing value and any other aggregate or mix property. This high correlation can be explained by the fact that weak aggregates tend to be easily crushed thus giving high crushing values. At the same time, the fines generated from crushing these aggregates tend to increase their surface area thus reducing actual film thickness.

It was expected that crushing value will highly correlate with Los Angeles abrasion test results, but this is not the case probably because material variability and/or testing errors.

Surface constant ( $K_{m}$ ) was found to be highly correlated with only Los Angeles abrasion test and added surface area. This is logical since all three properties can be linked to either weakness or high surface voids or both.

\section{Conclusion}

1. Not all aggregates obtained from the Riyadh area satisfy the Saudi Standards for use asphalt concrete mixes. 


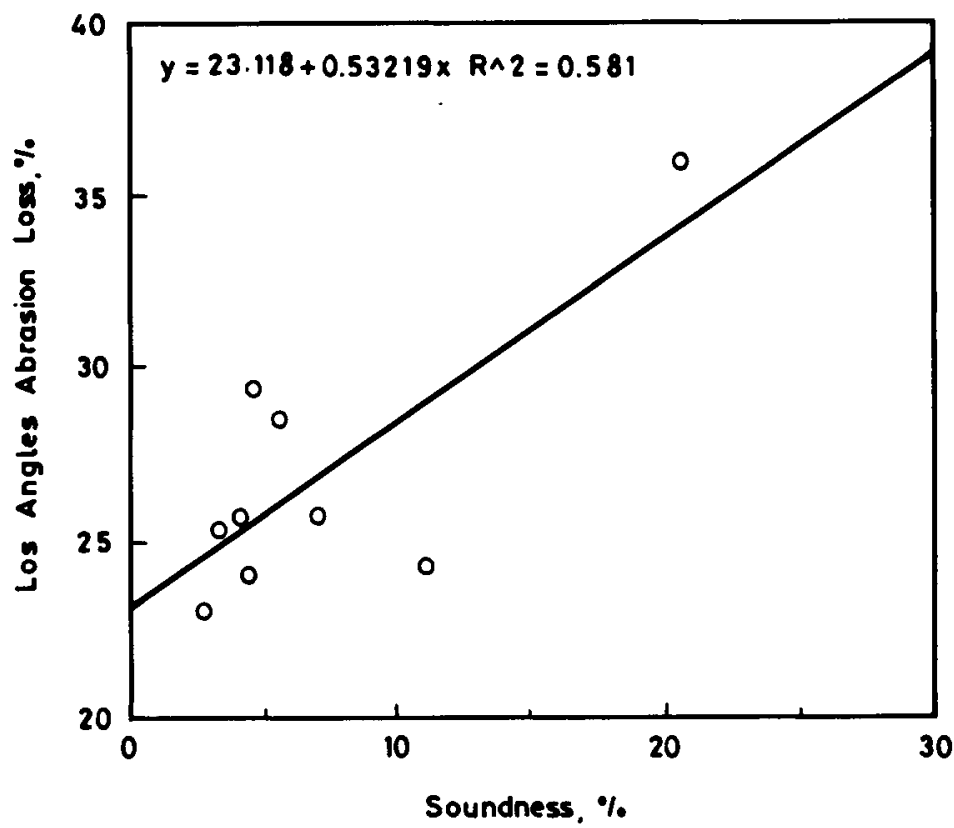

FIG. 11. Los Angeles abrasion loss vs. soundness.

2. In general, analyses of variance of mixes' properties show that there is a significant difference among various aggregate sources used in this study.

3. Differences between original and after-compaction gradation of aggregates indicate that the Marshall compaction process caused aggregates to disintegrate thus changing the gradation and generating more fines. This has a profound effect on the properties of laboratory-made specimens.

4. Since specimens compacted by Marshall hammer may not simulate field compaction, the use of laboratory specimens compacted by Marshall hammer for mix design is questionable.

5. Low quality aggregates produced mixes with high max. Marshall stability. This could be misleading in many instances.

6. Max. Marshall stability was found to be highly correlated to a number of aggregate properties such as loss in Los Angeles abrasion test, bulk specific gravity and water absorption.

7. Dry ITS and dry $M_{R}$ were found not to be highly correlated with any other single property of either aggregates or mixes. However, graphs show a general trend of decreasing dry $I T S$ and $M_{R}$ values as the aggregate quality decreases. To the contrast, wet ITS and wet $M_{R}$ were found to be highly correlated with each other and with a number of aggregates' properties.

8. Loss in Los Angeles abrasion test, soundness, and water absorption were found to be highly correlated with each other, which means one can be used as an indication of the others. 
Abbreviation List

$A C \quad$ Asphalt content

$A V \quad$ Air voids

M. St. Marshall stability

DITS Dry indirect tensile strength

WITS Wet indirect tensile strength

$D M_{R} \quad$ Dry resilient modulus

$W M_{R} \quad$ Wet resilient modulus

RITS Retained indirect tensile strength (WITS/DITS)

$R M_{R} \quad$ Retained resilient modulus $\left(W M_{R} / D M_{R}\right.$ )

\section{References}

[1] Brown, E.R., McRae, J. and Crawley, A., Effect of aggregate on performance of bituminous concrete, ASTM STP, 1016: 34-63 (1989).

[2] Gandhi, P. and Lytton, R., Evaluation of aggregates for acceptance in asphalt paving mixtures, Proceedings of The Association of Asphalt Paving Technologists, 53: 525-558 (1984).

[3] Zein Al-Abidien, H., Properties of the aggregates for concrete in Saudi Arabia, The First Saudi Engineering Conference, Jeddah, May (In Arabic) (1983).

[4] Rashid Geotechnical \& Materials Engineers, Evaluation of quarry and aggregate crusher of the United Company for Maintenance and Contracting in Wadi Laban, Technical Report, Project No. 880698 (In Arabic) pp. 1-12 (1988).

[5] Al-Mokayad, R., A Laboratory Evaluation of Moisture-Induced Damage to Asphalt Concrete Mixes Used in Riyadh Streets, M.Sc. Thesis, College of Engineering, King Saud University, Riyadh, pp. 3570 (1990).

[6] Hughes, C.S., Compaction of asphalt pavement, Synthesis of Highway Practice, 152, Transportation Research Board, NCHRP, Oct. (1989).

[7] Aunan, R.B., Luna, R., Altschaefn, A. and Wood, L., Reproduction of thin bituminous surface course fabric by laboratory compaction procedures. Transportation Research Board, Transportation Research Record, 1171, pp. 178-183 (1988). 
تأثـــــر خــــواص الركام على الخلــــــات الأسفلتيــــة

$$
\begin{aligned}
& \text { عبد الرحمن صالح السحيباني }
\end{aligned}
$$

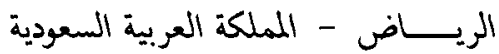

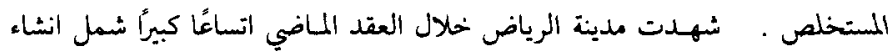

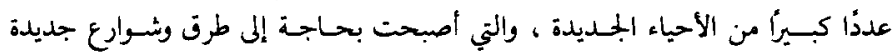

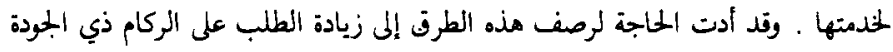

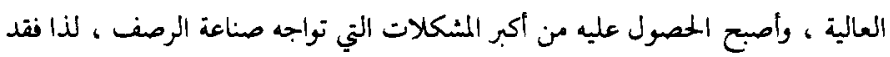

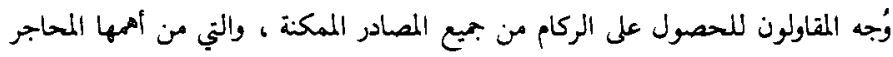

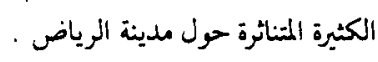

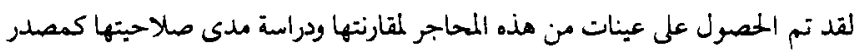

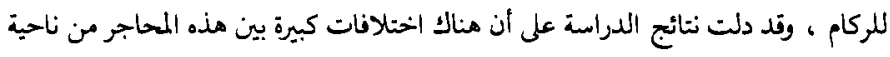

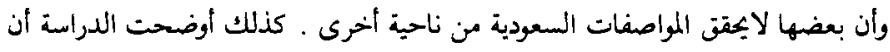

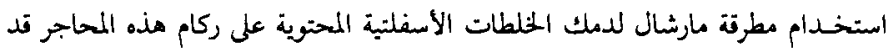

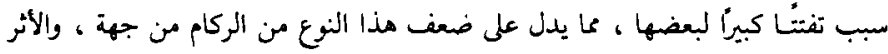

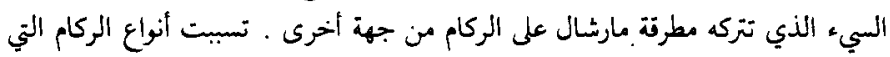

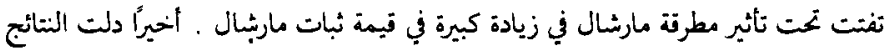

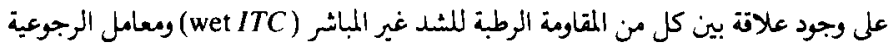

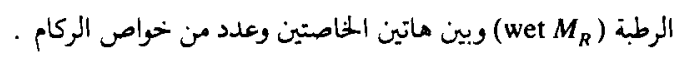

